\title{
THE NATURE OF THE PERIPHERAL RESISTANCE IN ARTERIAL HYPERTENSION WITH SPECIAL REFERENCE TO THE VASOMOTOR SYSTEM
}

\author{
BY MYRON PRINZMETAL 1 AND CLIFFORD WILSON 2 \\ (From the Thorndike Memorial Laboratory, Second and Fourth Medical Services (Harvard), \\ Boston City Hospital, and the Department of Medicine, Harvard Medical School, Boston)
}

(Received for publication August 22, 1935)

From the physiological point of view elevation of blood pressure may be due to an increase in cardiac output, in the volume or viscosity of the blood or in the resistance of the peripheral vessels. Since cardiac output is not increased in hypertension $(1,2,3)$ and the viscosity (4) and volume (5) of the circulating blood have been shown to be normal, there remains only the increased resistance in the peripheral circulation.

From an analysis of the literature it appears that investigations on the exact nature of this increase in peripheral resistance are comparatively few in number and have led to conflicting results. It is the purpose of this paper to deal with the following questions.

$A$. Is the increased peripheral resistance generalized throughout the systemic circulation or confined to the splanchnic area?

$B$. To what extent are the vessels responsible for the increased peripheral resistance capable of dilatation?

$C$. What part is played by the vasomotor nerves in the maintenance of the increased peripheral resistance; i.e. if arterial hypertonus is present can it be attributed to an increase in sympathetic vasoconstrictor impulses?

We have attempted to answer these questions by studies on the blood flow in the arm under various conditions, using the arm plethysmograph as described by Lewis and Grant (6), and to determine whether the nature and distribution of the increased resistance is the same in the different forms of hypertension, which have been designated benign, malignant and secondary (" renal ") hypertension.

1 National Research Council Fellow in Medicine.

2 Rockefeller Fellow in Medicine.
A. IS THE INCREASED PERIPHERAL RESISTANCE GENERALIZED THROUGHOUT THE BODY OR LIMITED TO THE SPLANCHNIC AREA?

\section{Literature}

In view of the known physiological importance of the splanchnic circulation it is essential to determine whether the development of hypertension in man is especially due to abnormal behavior of this vascular area. Various forms of evidence have been brought forward to support this possibility. In the first place, pathological studies show that the arterial lesions in hypertension are most intense in the splanchnic region, especially in the kidneys, adrenals, and pancreas. It appears, however, that no constant relationship exists between the severity of arteriosclerosis in the splanchnic area and high blood pressure. Longcope and $\mathrm{McClintock}$ (7) obtained transitory elevation of blood pressure by sudden occlusion of the splanchnic vessels in dogs. They attribute this effect to the increase in peripheral resistance, but find no evidence for regarding the splanchnic area as specifically important in the production of hypertension. Jansen, Tams and Achelis (8) found in animals that obstruction of the circulation to a limb caused a greater rise in blood pressure if the splanchnic vessels were first occluded. In subjects with hypertension they state that binding an extremity produced a higher and more sustained elevation of blood pressure than in normal individuals, and conclude from these results that hypertension is due to vasoconstriction in the splanchnic area. Splanchnic section has been performed $(9,10)$ in patients with hypertension on the basis of the same assumption, and lowering of the blood pressure has been alleged to follow such operations. Critical examination of the above experiments, however, fails to furnish any conclusive evidence that the increased vascular resistance is confined to the 
splanchnic area. Moreover, in certain forms of high blood pressure, e.g. eclampsia and malignant hypertension, vascular spasm may be observed in the retinal vessels. Volhard (11) has attributed pallor of the skin in such patients to generalized peripheral vascular spasm produced by a circulating pressor substance. There is, however, no conclusive evidence in support of this theory (12, 13, 14).

\section{Principle of method}

The cardiac output in patients with high blood pressure is known to be within normal limits (loc. cit.). If, therefore, hypertension is due to increased vascular resistance confined to the splanchnic area, the caliber of the vessels in the rest of the body remaining normal, the blood flow through the latter must be increased. If, on the other hand, the increased resistance is generalized and uniform, the blood flow in all parts of the systemic circulation will be the same as in normal individuals - the high blood pressure simply overcoming the increased resistance in all areas. This is in accordance with Poiseuille's law that the blood flow in any cross section of the vascular bed per unit time is directly proportional to the pressure and inversely proportional to the resistance. This may be expressed as a simple equation, $V \infty(P / R)$, where $V$ is the volume of blood flowing through an organ per unit of time, $P$ is the effective arterial pressure, and $R$ the resistance.

We have therefore compared the blood flows in the arm in patients with hypertension and in subjects with normal blood pressure. If the resting blood flow in the arm in patients with hypertension is equal to that in normal individuals, the peripheral resistance in the vessels of the arm must be increased to the same degree as the mean peripheral resistance in the splanchnic area. ${ }^{3}$ If, however, the peripheral resistance in the splanchnic area is greater than in other parts of the systemic circulation, the blood flow in the arm in hypertension will be greater than in normal individuals.

\footnotetext{
3 When referring to the mean peripheral resistance in the splanchnic area we recognize the possibility that the increased peripheral resistance may not actually be uniform throughout the organs in this area.
}

\section{Method of determination}

Brodie (15) has shown that when an organ is placed in an oncometer connected to a volumetric recorder, obstruction of the venous outflow causes an increase in size of the organ due to inflow of unobstructed arterial blood. This inflow can be measured for only a few seconds after venous occlusion, since congestion of the organ causes a rapid diminution of arterial flow. Hewlett and van Zwaluwenburg (16) applied this principle to man by enclosing the arm in a plethysmograph and occluding the venous return by a pneumatic cuff at a pressure just below diastolic. From the increase in arm volume per unit time the blood flow may be determined. The arm volume is measured, and the blood flow expressed in cubic centimeters per $100 \mathrm{cc}$. arm volume per minute. Hewlett and van Zwaluwenburg found the blood flow to be somewhat above normal in patients with hypertension. Unfortunately, they paid no attention to the type of hypertension or to the temperature of the arm during their experiments.

The arm plethysmograph of Lewis and Grant is admirably adapted to our purpose. It has a great advantage in excluding the hand, which shows vasomotor responses of great intensity attributable to the relatively large area of highly specialized skin (17). By means of the arm plethysmograph we can study a more representative segment consisting chiefly of striated muscle, fat and fascia covered by a more " normal" skin area. In using the plethysmograph, the most important practical point is to insure water-tight junctions where the arm enters and leaves the plethysmograph, without producing appreciable venous congestion. We were unable to obtain rubber tires of sufficient flexibility to follow Lewis's method, and used instead the cuffs of surgical rubber gloves, which are available in all sizes. These are prevented from bulging inwards or outwards by rings of hard rubber placed on either side, the whole being held in position by a metal lid which fits tightly onto the end of the plethysmograph (Figure 1, inset).

The arrangement of apparatus is shown in the accompanying diagram (Figure 1). The patient is seated comfortably in a wheel chair in a semireclining position. The plethysmograph is fitted 

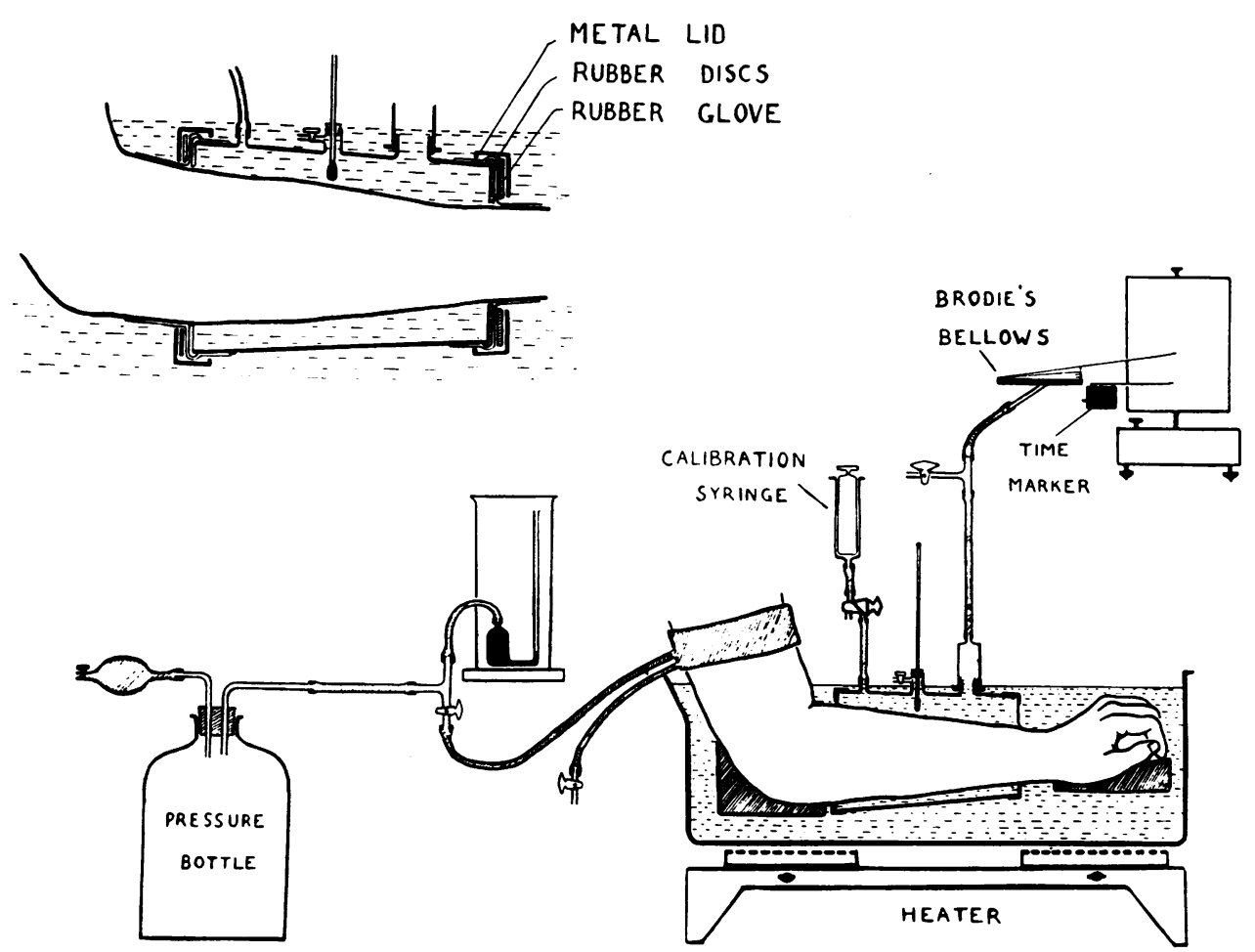

Fig. 1. Arrangement of Apparatus.

(After Lewis and Grant (6).)

onto the forearm, and filled with water at $24^{\circ} \mathrm{C}$. Since the volume of the plethysmograph is known, the arm volume can be readily obtained. The arm is placed in a water bath at the same temperature, and the plethysmograph connected to a 35 cc. Brodie's bellows by means of which volume changes are recorded on a smoked drum. Calibration is performed by the syringe as shown in the diagram, a $5 \mathrm{cc}$. increment in volume giving approximately $1.5 \mathrm{~cm}$. rise on the drum. A $6 \mathrm{~cm}$. pneumatic cuff, connected with a mercury manometer and pressure bottle, is fixed on the upper arm. It is important to guard against constriction on the veins by the upper plethysmograph cuff. Hence, at the outset, the venous pressure is measured by determining the lowest pressure in the sphygnomanometer cuff which will cause an increase in arm volume. This is usually about 5 to $10 \mathrm{~mm}$. of mercury. Certain precautions are essential in order to obtain comparable results: after the plethysmograph is in position an interval of at least half an hour should be allowed to elapse until the blood flow becomes constant. All the experiments here reported were performed at the same room temperature ( 70 to $72^{\circ} \mathrm{F}$.) since variations in the latter cause alteration in flow. Determinations were made at approximately the same time after the last meal (one to two hours) owing to the effect of digestion on the cardiac output (18). Psychic factors exert a considerable influence on the blood flow; hence such distractions as reading and talking were avoided. Under these uniform conditions average blood flows can be obtained on the same patient on different occasions with an experimental error of not more than 15 per cent. Reference to the tables shows a great individual variation. This is only to be expected in view of the physiological nature of the experiment and correspondingly wide variations in cardiac output. These variations are no greater in patients with hypertension than in conrols. Four to ten blood flow determinations were made, the average of which is taken as the resting flow. Figure 2 shows typical blood flows. 


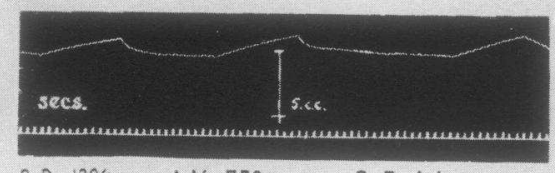

S.P. $120 / 85$ A.V. 750 ec. B. F. 1.4 ce.

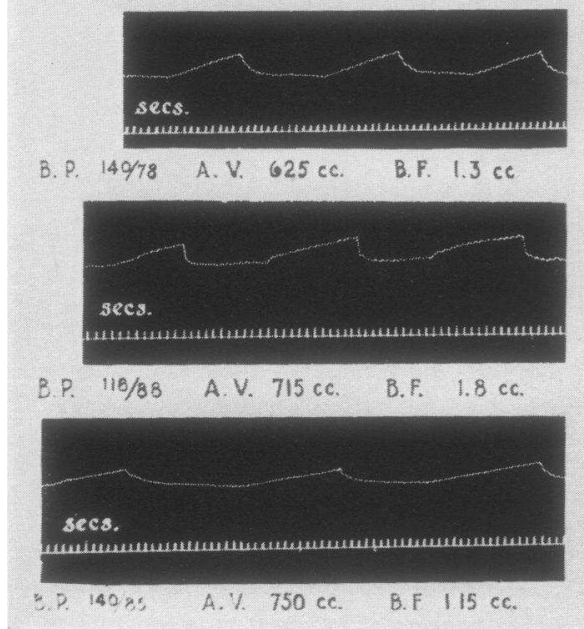

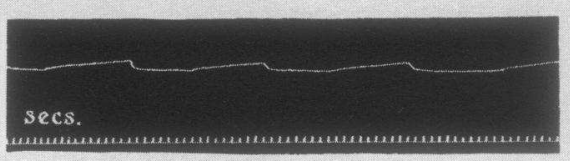
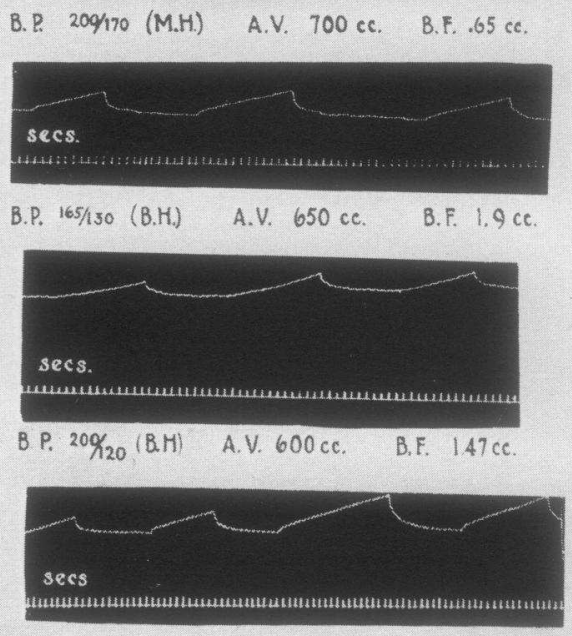

B.P. $25 \% 150$ (B.H) A.Y. $520 \mathrm{cc}$ B F $145 \mathrm{cc}$

Patients with Hypertension.

Fig. 2. Resting Blood Flows.
B.P.--blood pressure.
B.H.-benign hypertension.
A.V.-arm volume.
M.H.-malignant hypertension.
B.F.-blood flow (cc. per 100 cc. arm volume per minute).

\section{Classification of cases}

According to the prevailing classification, the cases studied fall under the headings of benign, malignant, and secondary (renal) hypertension. The diagnosis of benign hypertension was made in fifteen patients on the basis of a slowly progressing hypertension of many years' duration. Kidney function tests were normal, and the previous history showed no evidence of renal disease. Hypertensive retinopathy of the type described below was absent. A diagnosis of malignant hypertension was made in seven cases. These patients were relatively young (12 to 47 years), a previous history of acute nephritis was absent, the blood pressure was comparatively high and the condition rapidly progressive. Clinical and laboratory evidence of renal impairment was present and hypertensive retinopathy was found in all cases. The characteristic ophthalmoscopic findings were papilledema and retinal edema, narrowing of the arteries, and in all cases except one, retinal exudates. The diagnosis was confirmed at autopsy in one of these subjects. In the group of "secondary" hypertension were placed ten patients with chronic renal disease. Renal impairment was present in all. Six were cases of subacute or chronic glomerulonephritis, and in one the diagnosis was confirmed at autopsy. One patient had acute glomerulonephritis, the diagnosis being confirmed at autopsy. Of the remainder, three were diagnosed as chronic pyelonephritis, one originating in pregnancy and two associated with kidney stones and bilateral stenosis of the ureters. Patients showing any evidence of cardiac failure were excluded from the investigation.

\section{Results}

\section{Patients with hypertension compared with con- trols}

As indicated in Table I and Figure 2, the average resting blood flow in eighteen normal subjects was $1.65 \mathrm{cc}$. per $100 \mathrm{cc}$. arm volume per minute. The average flow for 32 cases (all types) of hypertension was $1.52 \mathrm{cc}$. In benign hyper- 
TABLE I

Resting blood flow

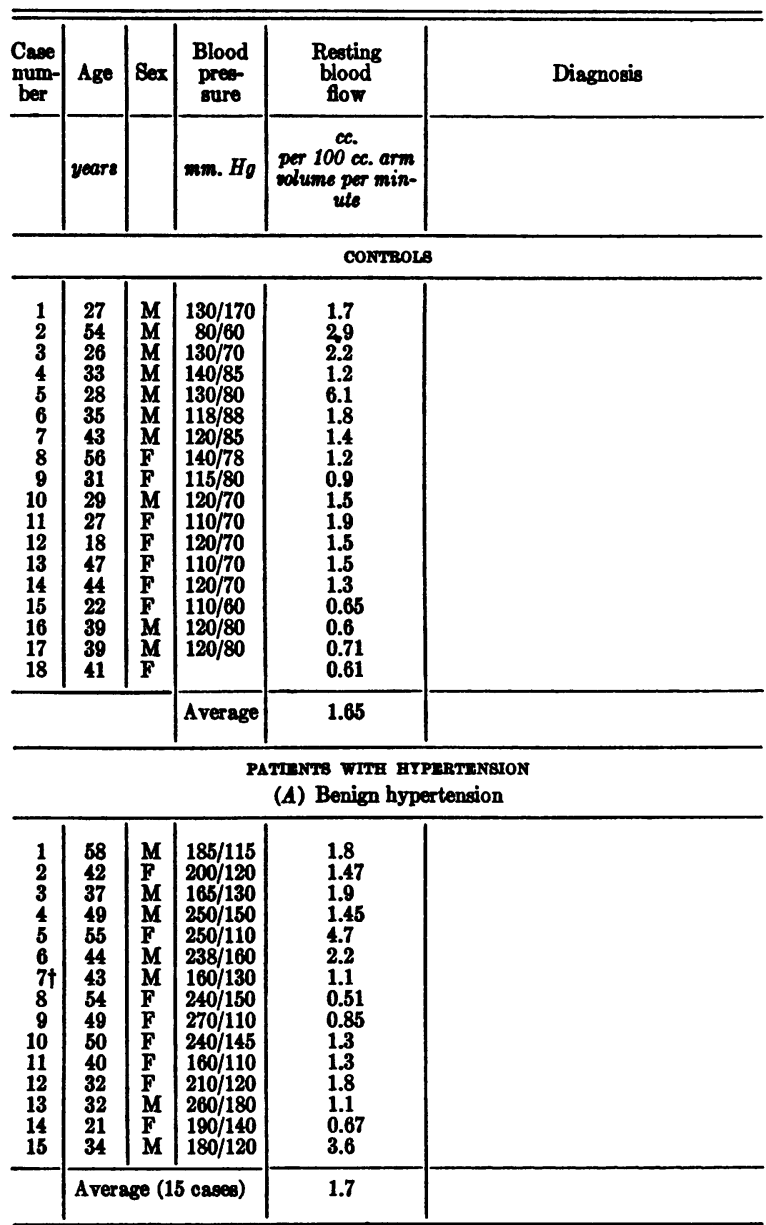

(B) Malignant hypertension

\begin{tabular}{c|c|c|c|l|l}
\hline 16 & 47 & $\mathrm{M}$ & $220 / 140$ & 1.75 & \\
17 & 16 & $\mathrm{~F}$ & $205 / 150$ & 2.0 & \\
18 & 30 & $\mathrm{~F}$ & $270 / 180$ & 1.1 & \\
$19^{*}$ & 12 & $\mathrm{~F}$ & $210 / 170$ & 1.5 & \\
20 & 40 & $\mathrm{~F}$ & $190 / 140$ & 2.3 & \\
21 & 39 & $\mathrm{M}$ & $200 / 170$ & 0.65 & \\
$7 \dagger$ & 44 & $\mathrm{M}$ & $245 / 185$ & 1.05 & \\
\hline & \multicolumn{2}{|c|}{ Average (7 cases) } & 1.5 & \\
\hline
\end{tabular}

(C) Secondary hypertension

\begin{tabular}{|c|c|c|c|c|c|}
\hline $\begin{array}{l}22 \\
23 \\
24 \\
25 \\
26 \\
27^{*} \\
28 \\
29^{*} \\
30 \\
31\end{array}$ & $\begin{array}{l}38 \\
40 \\
22 \\
60 \\
15 \\
42 \\
27 \\
42 \\
43 \\
23\end{array}$ & $\begin{array}{l}\mathbf{M} \\
\mathbf{M} \\
\mathbf{F} \\
\mathbf{F} \\
\mathbf{M} \\
\mathbf{F} \\
\mathbf{M} \\
\mathbf{F} \\
\mathbf{F}\end{array}$ & $\begin{array}{l}200 / 150 \\
170 / 105 \\
158 / 110 \\
170 / 105 \\
170 / 100 \\
210 / 105 \\
200 / 110 \\
190 / 100 \\
250 / 150 \\
210 / 140\end{array}$ & $\begin{array}{l}1.4 \\
1.05 \\
0.7 \\
0.7 \\
0.7 \\
3.3 \\
1.3 \\
0.7 \\
1.1 \\
1.8\end{array}$ & $\begin{array}{l}\text { Chronic glomerulonephritis } \\
\text { Chronic glomerulonephritis } \\
\text { Subacute glomerulonephritis } \\
\text { Kidney stones. Pyelonephritis } \\
\text { Subacute glomerulonephritis } \\
\text { Chronjc glomerulonephritis } \\
\text { Chronic glomerulonephritis } \\
\text { Acute glomerulonephritis } \\
\text { Kidney stones. Pyelonephritis } \\
\text { Pyelonephritis }\end{array}$ \\
\hline & \multicolumn{3}{|c|}{ Average (10 cases) } & 1.3 & \\
\hline \multicolumn{4}{|c|}{$\begin{array}{l}\text { Average all types of hyper- } \\
\text { tension (32 cases) }\end{array}$} & 1.52 & \\
\hline
\end{tabular}

* Died-Diagnosis confirmed at autopsy.

† Case 7 is included twice as explained in text. tension (fifteen cases) $1.7 \mathrm{cc}$; in malignant hypertension (seven cases) $1.5 \mathrm{cc}$; in secondary hypertension (ten cases) $1.3 \mathrm{cc}$.

\section{Effect on blood flow of variations in blood pressure in the same individual}

We were fortunate in obtaining blood flows in two cases at considerably different levels of the blood pressure.

Case 1. Acute exacerbation of hypertension (Number 7, Table II $A$ ). This patient, a 43-year-

TABLE II

( $A$ )

Resting blood flow in Case 7 during benign and malignant phases of hypertension

\begin{tabular}{c|c|c}
\hline \hline Date & Blood pressure & Resting blood flow \\
\hline 1935 & $\mathrm{mm.} \mathrm{Hg}$ & $\begin{array}{c}\text { cc. per } 100 \text { cc. arm } \\
\text { volume per minute }\end{array}$ \\
February $12 \ldots \ldots \ldots \ldots$ & $160 / 130$ & 1.1 \\
May $1 \ldots \ldots \ldots \ldots \ldots$ & $245 / 185$ & 1.05 \\
\hline
\end{tabular}

(B)

Resting blood flow in patient with benign hypertension and postural hypotension

\begin{tabular}{c|c|c|c}
\hline \hline Position & $\begin{array}{c}\text { Blood } \\
\text { pressure }\end{array}$ & Cardiac output & Resting blood flow \\
\hline & $\begin{array}{c}\text { liters per minute } \\
\text { per square meter } \\
\text { body surface }\end{array}$ & $\begin{array}{c}\text { cc. per 100 cc. } \\
\text { arm volume per } \\
\text { minute }\end{array}$ \\
Horizontal ..... & $195 / 100$ & 2.60 & .37 \\
Upright...... & $100 / 75$ & 2.64 & .38 \\
\hline
\end{tabular}

old man, on first admission had a history of hypertension of three years' duration with no evidence of pre-existing kidney disease. Blood pressure was $160 / 130 \mathrm{~mm}$. Hg. Renal function tests were normal, and ophthalmoscopic examination was negative. A diagnosis of benign hypertension was made. Three months later he was admitted complaining of nocturia, headaches, and dimness of vision. Blood pressure was 245/185 $\mathrm{mm}$. $\mathrm{Hg}$ and renal impairment with nitrogen retention was present. The fundi showed hypertensive retinopathy (papilledema and exudates). The diagnosis of malignant hypertension was now made. Blood flows measured on both occasions showed identical values.

Case 2.4 Benign hypertension with postural

4 We were permitted to study this case through the courtesy of Dr. L. B. Ellis and Dr. F. W. Haynes. 
hypotension (Table II $B$ ). This patient, a 69year-old woman, complained of weakness and dizziness on standing up. There was a history of diabetes mellitus, high blood pressure, and combined system disease of several years' duration. In the recumbent position the blood pressure was $195 / 100$, falling to $120 / 90$ to $70 / 65$ on standing. The cardiac output, determined by the acetylene method, showed no change with position, in spite of the variation in blood pressure. We have measured the resting blood flow in the arm in the recumbent and in the erect posture and found identical values.

\section{Discussion}

These results demonstrated that the blood flow in the arm of subjects with hypertension is no greater than in normal individuals. For the reasons already given we must conclude that increased vascular resistance in hypertension is no greater in the splanchnic area than in the arm, that is, we are dealing with a generalized increase in peripheral resistance throughout the systemic circulation. If this were not the case and the caliber of the arm vessels remained unaltered, an increase of effective blood pressure by two-thirds the normal value would (according to Poiseuille's law) give a blood flow 1.5 times the normal, i.e. approximately $2.65 \mathrm{cc}$. per $100 \mathrm{cc}$. arm volume.

Our deduction is valid only so long as there is no marked diminution in the cardiac output in hypertension. Most observers are agreed on this point, though Weiss and Ellis (3) found that in some cases the output is at the lower limit of normal. Weiss, Haynes and Shore (19) in this clinic have recently reinvestigated the question by the Grollman method (18). The results, which they have kindly placed at our disposal, show no diminution in cardiac output in hypertension.

The results in the two patients where it was possible to obtain blood flows at different levels of blood pressure confirm the above conclusions. In both cases there was no increase in blood flow when the blood pressure changed to a higher level. This indicates in Case 1 that the exacerbation of the hypertension was produced by a generalized increase in peripheral resistance, the distribution of which was the same before and after the malignant phase. Similarly, in Case 2 the increase in blood pressure on changing from the erect to the recumbent posture appears to be associated with a generalized increase in peripheral resistance. The results indicate also that the fall in blood pressure in this case of postural hypotension is a generalized phenomenon, i.e. is not produced by changes confined to the splanchnic area.

\section{B. TO WHAT EXTENT ARE THE VESSELS CAPABLE OF DILATATION IN SUBJECTS WITH HYPERTENSION?}

\section{Literature}

In cases of acute hypertension (e.g. acute nephritis and eclampsia) where the blood pressure may fall rapidly to the normal level, and in cases of fluctuant hypertension which returns to normal between the periods of exacerbation, the blood vessels are apparently capable of dilatation. In the majority of cases, however, the pressure is maintained above normal and may become "fixed" at a high level. Such a "fixation" has been ascribed to organic changes in the blood vessels (20). The histological evidence of diffuse arterial lesions in hypertension is, however, not conclusive and will be discussed later. Volhard (11) holds the somewhat different view that arteriosclerosis of the renal vessels is responsible for the "red" or benign form of hypertension and refers to the increased peripheral resistance in these cases as "passive" in contrast to the "active" spasm in "white" hypertension. Pal (21) maintains on clinical grounds that hypertonus is present in the palpable arteries in hypertension, but furnishes no experimental proof of this.

Brown and Alexander have recently shown (22) that the percentage of patients with hypertension who develop Duroziez's sign on placing the arm in hot water is less than in subjects with normal blood pressure. They conclude from these findings that in hypertension the minute vessels are unable to dilate sufficiently to produce a diastolic murmur. Abnormal responses to heat, cold, and arterial occlusion $(23,24)$ have been reported in hypertension, but the conflicting nature of the results makes their interpretation difficult. There appears in fact to be no conclusive experimental evidence which demonstrates the capacity of the peripheral vessels to dilate in the different forms of hypertension compared with normal individuals. 


\section{Principle of method}

Vascular dilatation can be produced in normal individuals by two simple methods: (1) Direct application of heat and (2) by reactive hyperemia following arterial occlusion. Dilatation of the vessels by heat is probably a combined result of sympathetic vasodilatation and the direct effect on the vessels of increase in temperature. In reactive hyperemia Lewis and Grant (6) have shown that dilatation is caused by the action of metabolites on the vessels, although it appears that vasomotor impulses may modify the response (25). Thus, while both are physiological responses, the mechanism of production is different. We have compared the effects of these procedures on the blood flow in the arm in normal individuals and in patients with hypertension.

\section{Methods of determination}

After the resting blood flow in the arm at $24^{\circ}$ C. has been recorded, the temperature of the water bath is gradually raised ( $5^{\circ}$ in ten minutes). When the plethysmograph temperature reaches $45^{\circ} \mathrm{C}$. the heater is turned off, and blood flows recorded until constant values are obtained (10 to 20 minutes).

As an indication of the degree of vascular dilatation produced by reactive hyperemia, the blood flow is determined in all cases ten seconds after circulatory release. The procedure is as follows: A pressure above the systolic is maintained in the sphygmomanometer cuff for five minutes. A slight increase in arm volume may occur during this period due to the collateral circulation in the bones (6). On releasing the pressure, there is an increase in arm volume which is recorded on a fast drum. Exactly ten seconds after release a determination of blood flow' is made as previously described, i.e. by throwing into the cuff a pressure just below diastolic. Although the blood flow may not be maximal at this time, a ten-second interval was arbitrarily chosen in order to permit the initial increase in arm volume to reach its maximum.

Blood flows during reactive hyperemia were obtained at $24^{\circ} \mathrm{C}$. and $40^{\circ} \mathrm{C}$. Five-minute arterial occlusion is usually too painful to allow determinations above the latter temperature.

\section{Results}

The results are shown in Table III, $A$ and $B$, and Figures 3 and 4 . The ability of the vessels to open up is expressed as the ratio of the flow at $45^{\circ}$ C. to the flow at $24^{\circ}$ C. Similarly, blood flows during reactive hyperemia are expressed as ratios to the resting blood flows at the corresponding temperatures. Thus under the influence of heat the average ratio for normal individuals is 10.2 ; for cases of benign hypertension 11.6, malignant hypertension 10.9 , and secondary hypertension 14.0. Average for all cases of hypertension 12.0.

Reactive hyperemia at $24^{\circ} \mathrm{C}$. gives average ratios of 9.9 (controls); 13.5 (benign hypertension) ; 13.7 (malignant hypertension) ; 11.6 (secondary hypertension). The average of all cases of hypertension is 13.2.

Reactive hyperemia at $40^{\circ} \mathrm{C}$. gives ratios of 1.97 (controls) ; 1.95 (benign) ; 2.1 (malignant); 1.8 (secondary). The average of all cases of hypertension is 1.96 .

\section{Discussion}

These results demonstrate that in all forms of hypertension the blood vessels of the arm are capable of considerable dilatation, sufficient in fact to cause an increase in blood flow equal to that in normal individuals. Our findings do not confirm the abnormal responses to heat and reactive hyperemia in hypertension reported elsewhere $(23,24)$. The fact that the blood vessels in hypertension are capable of opening up 15 to 20 times (as indicated by the ratio of the resting flow at $24^{\circ} \mathrm{C}$. to the reactive hyperemic flow at $40^{\circ} \mathrm{C}$.) strongly suggests that the increased vascular resistance in hypertension is not due to organic changes of the vessel walls. If this were the case, some diminution in the response to heat and metabolites might be expected to occur. In fact, the physiological stimuli of heat and reactive hyperemia produce the same increase in blood flow in patients with hypertension as in normal individuals. It follows that in patients with hypertension the blood vessels still exhibit a relatively greater peripheral resistance than in normal subjects even at the height of vascular dilatation. This restriction of response to the limits of normal indicates the manner in which the vascular 

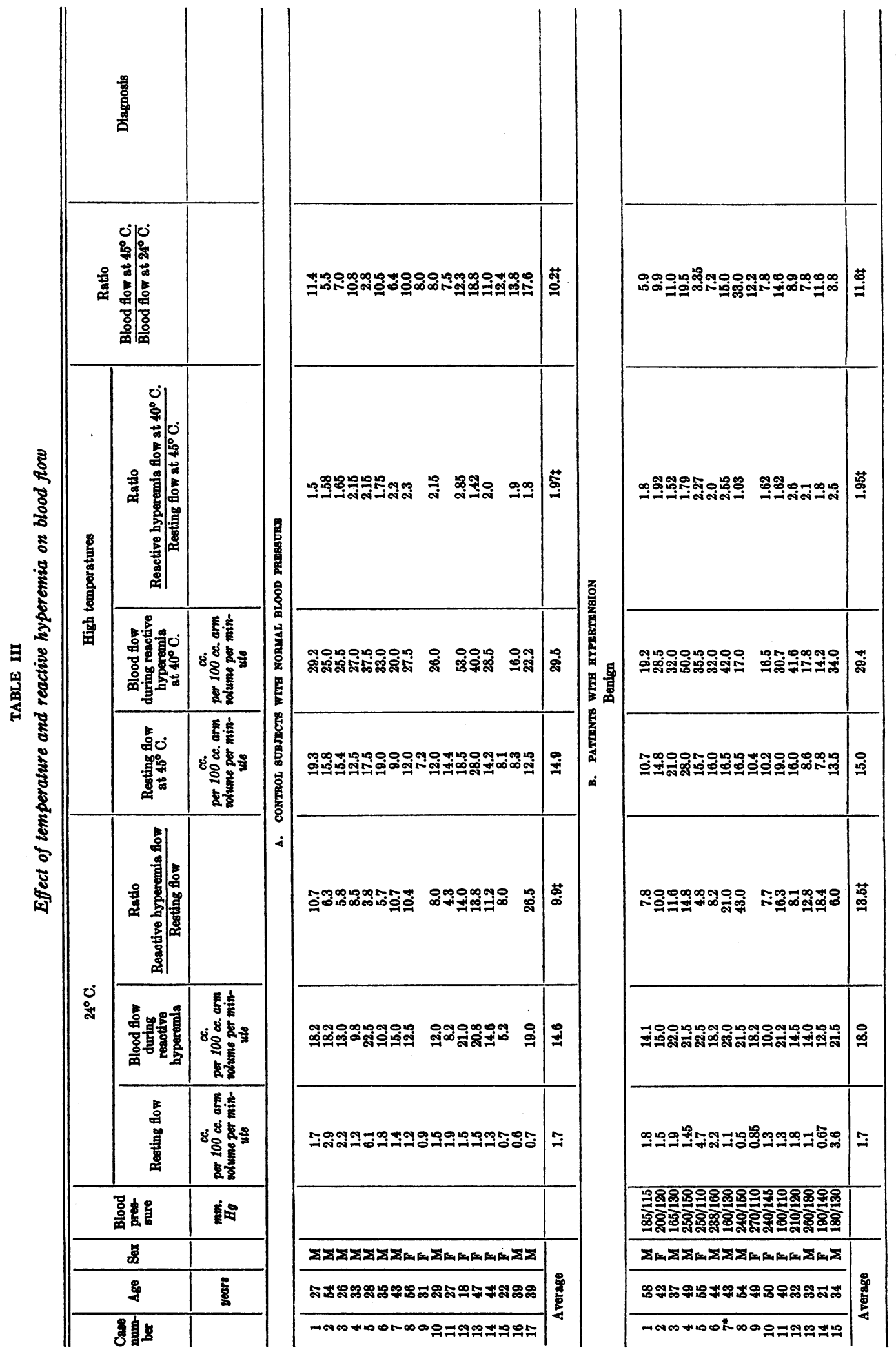


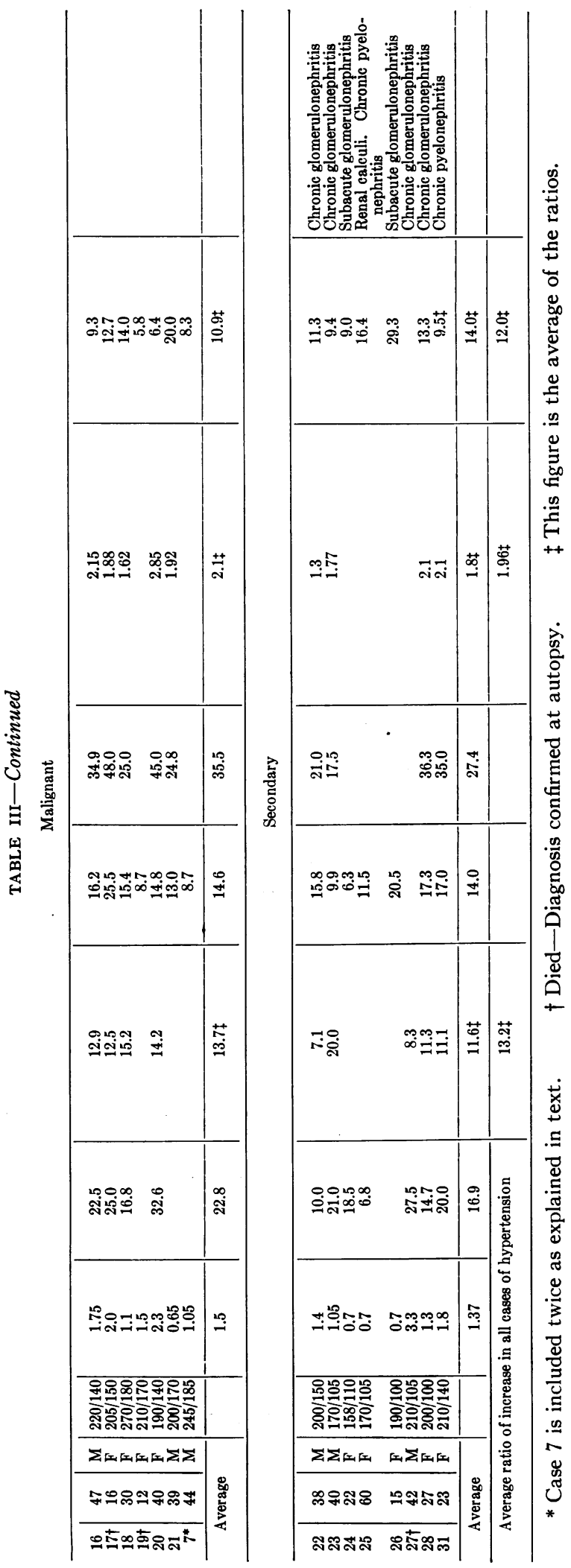

mechanism, acting at a higher level of blood pressure, is adapted to physiological requirements. Such an efficient adaptation demonstrates the ability of the vessels to dilate, and makes it unlikely that any true organic rigidity is present.

From the physiological evidence we feel justified, therefore, in attributing the increased peripheral resistance in hypertension to a generalized vascular hypertonus, rather than to organic changes in the blood vessels. The histological evidence bears out this conclusion. Thus several observers have reported cases in which arteriosclerosis was minimal or absent even in the splanchnic area (41). Kernohan, Anderson and Keith (26) have described arteriolar lesions, chiefly in the nature of medial hypertrophy, in the voluntary muscles in hypertension, but state that such lesions are usually absent in the benign form. More recently, it has been shown histologically (27) that there is no diminution in the mean internal diameter of the small arteries and arterioles in the voluntary muscles in hypertension. A diminution in the arterial supply to the kidney has been found in advanced cases of hypertension $(42,43)$. It is also known that organic changes found in the arterioles of certain abdominal organs are more marked than those found in the voluntary muscles. It is theoretically possible that in some of these cases organic changes may contribute to the increase in peripheral resistance. However, these lesions are found in a small fraction of the total arteriolar system, and should cause but a slight increase in the mean peripheral resistance. The work of Goldblatt, et al. (37) adds additional evidence to this viewpoint. In their animals, hypertension did not occur until several hours after the renal arteries had been clamped. If obstruction of the renal arteries per se causes a significant increase in the mean peripheral resistance, the blood pressure should have risen immediately following the clamping procedure.

\section{RELATION OF THE VASOMOTOR NERVES TO HYPERTENSION}

\section{BENIGN HYPERTENSION}

\section{Literature}

Stimulation of the sympathetic nerves and of the vasomotor center is known to produce con- 

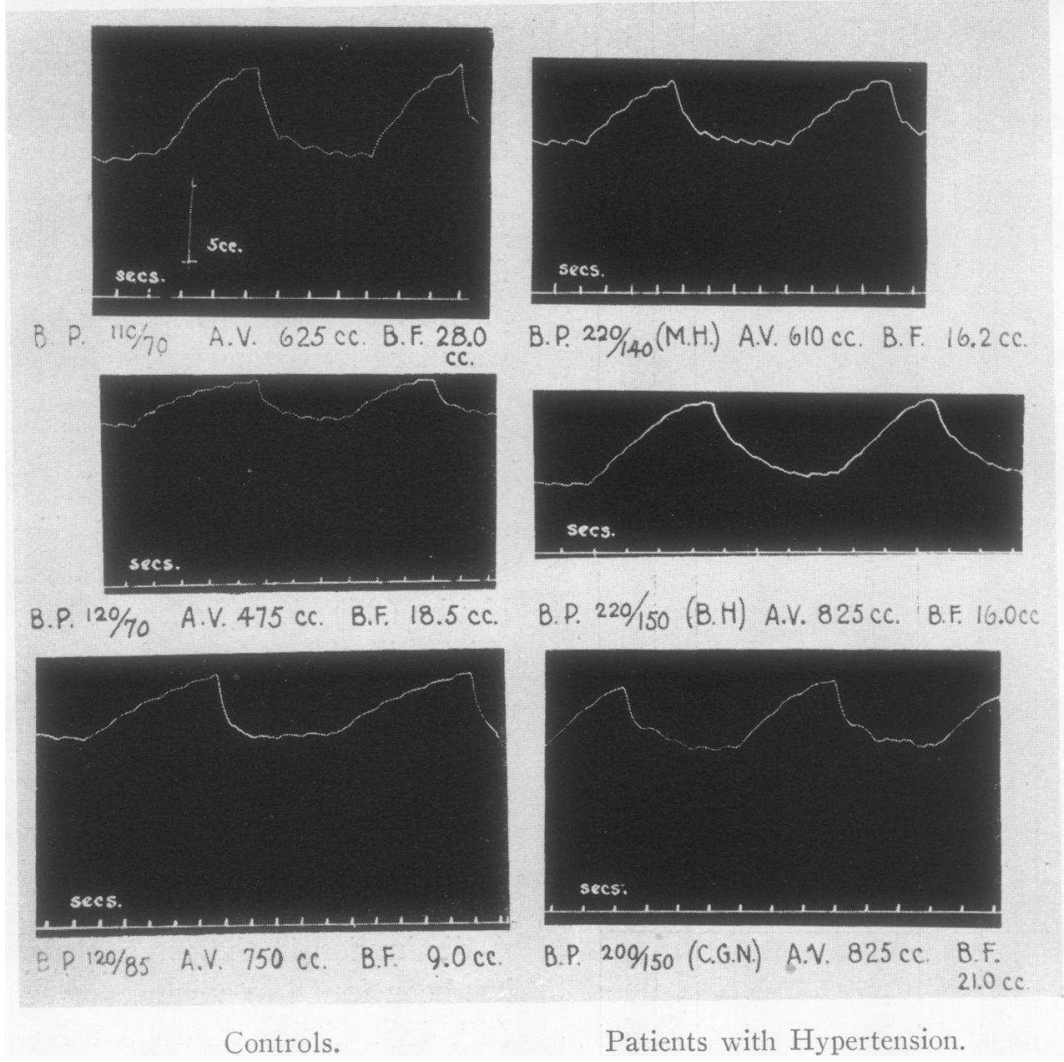

Fig. 3. Vasodilatation Produced by Heat ( $45^{\circ}$ C.). B.P.-blood pressure. B.H.--benign hypertension. A.V.-arm volume. M.H.-malignant hypertension. B.F.-blood flow (cc. per $100 \mathrm{cc}$. arm volume per minute). C.G.N.-chronic glomerulonephritis.

striction of the blood vessels and elevation of the blood pressure. Moreover, the results of nerve section indicate that the arterioles are usually in a state of tonus which is regulated in part by the vasomotor nerves. It has naturally been widely assumed that the increased vascular resistance in hypertension is due to exaggerated vasoconstrictor tone. We have, however, been unable to find any conclusive evidence in the literature which supports such a hypothesis. There are several experimental observations which suggest that in patients with hypertension the blood vessels react abnormally to certain stimuli. Thus, following immersion of the arm in ice water (20), inhalation of $\mathrm{CO}_{2}$ (28), painful stimuli (29), and exercise (30), an exaggerated response in the blood pressure has been observed in subjects with hypertension. It has been assumed that these results support the vasomotor theory of hypertension. The significance of these findings will be discussed later. On the basis of this neurogenic theory of hypertension certain surgical procedures, e.g. splanchnic nerve section, dorsal and lumbar ganglionectomy and anterior root section, have been performed in an attempt to lower the blood pressure. The poor therapeutic results which may follow such operations have been attributed either to incomplete removal of the vasomotor nerves or to fixation of the hypertension by organic changes in the blood vessels.

\section{Methods and results}

We have attempted to demonstrate the rôle of the vasomotor nerves in hypertension by two methods; namely by studying the increase in blood flow in the arm following (1) vasomotor dilata- 


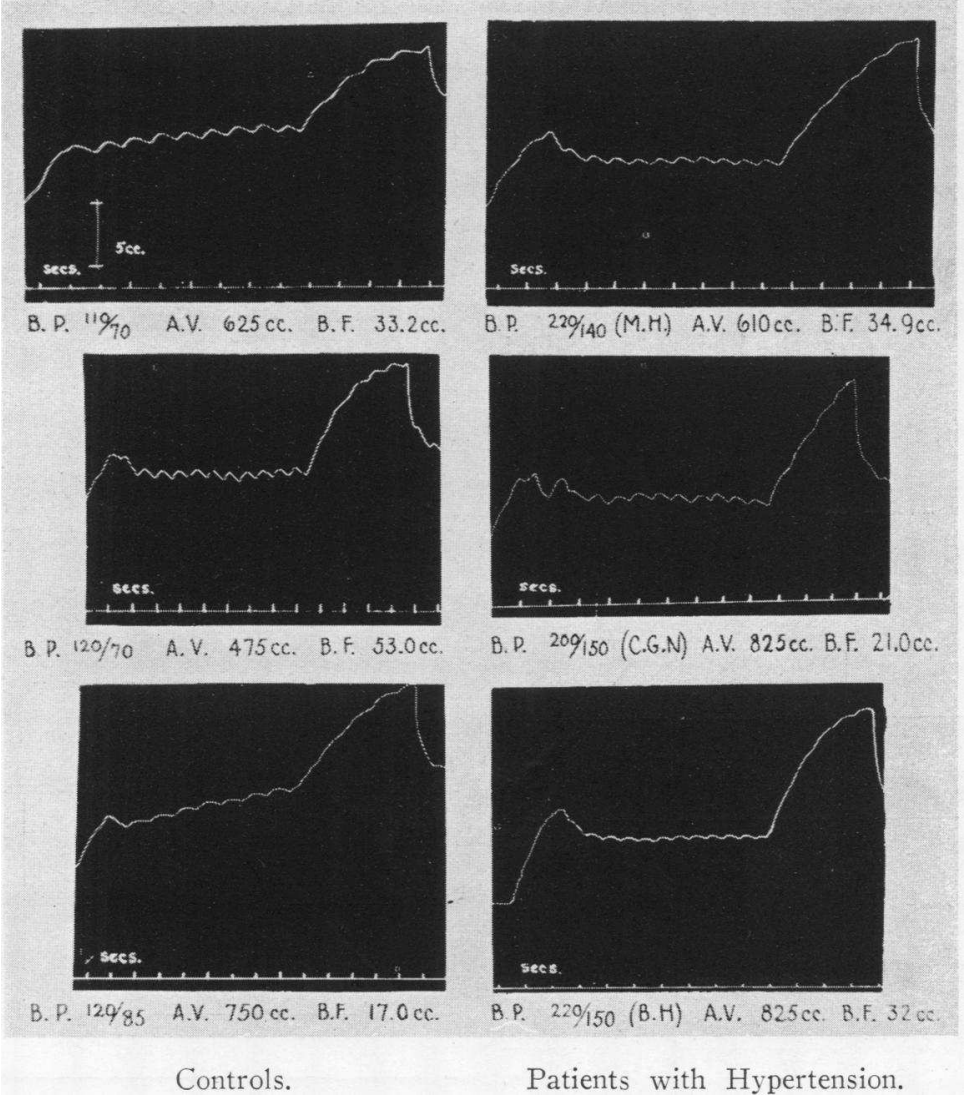

Fig. 4. Effect on Bloon Flow of Reactive Hyperemia at $40^{\circ} \mathrm{C}$.

B.P.-blood pressure. $\quad$ B.H.-benign hypertension.

A.V.-arm volume. $\quad$ M.H.-malignant hypertension.

B.F.-blood flow (cc. per $100 \mathrm{cc}$. arm volume per minute).

C.G.N.-chronic glomerulonephritis.

tion induced by heat and (2) blocking of vasomotor impulses by novocain injection of the dorsal sympathetic ganglia.

\section{Vasomotor dilatation induced by heat}

It is well known that when the body is heated vasodilatation of the peripheral vessels occurs, as evidenced by increase in skin temperature. This reaction is vasomotor in origin, since it is absent when the sympathetic nerves are cut. Furthermore, it has been shown that vasodilatation in the skin is produced not only by inhibition of vasoconstrictors, but also by stimulation of vasodilators (31).

We have used the heat test devised by Gibbon and Landis (32). After the resting blood flow in the arm has been determined, the opposite arm is placed in water at $45^{\circ} \mathrm{C}$., and the patient is kept warm with blankets. The blood flow begins to increase in ten to fifteen minutes and reaches its maximum value in thirty to sixty minutes, the maximum usually being attained about ten minutes after the subject begins to perspire freely.

In order to show that the above conclusions regarding the nature of the heat test could be applied to the blood vessels of the arm, as well as to those of the skin, we performed the test in two patients before and after sympathetic block for Raynaud's disease of the fingers.

Case 1. A 28-year-old woman with typical Raynaud's disease of the fingers was admitted to the Neurological Service of the Boston City Hospital and alcohol injection of the upper dorsal 
sympathetic ganglia was performed by Dr. Walter Wegner. Before injection the resting blood flow in the arm was $.65 \mathrm{cc}$. per $100 \mathrm{cc}$. arm volume, which increased to $1.75 \mathrm{cc}$. during the heat test. After alcohol injection the hand became hot and dry, a typical Horner's syndrome was present, and perspiration was absent on the side of the injection. The resting blood flow ten days later was $1.1 \mathrm{cc}$. and on performing the heat test showed not an increase but actually a slight decrease (Table IV).

\section{TABLE IV}

Effect of sympathectomy on resting blood flow and heat test

\begin{tabular}{|c|c|c|c|c|}
\hline \multirow{2}{*}{$\begin{array}{c}\text { Case } \\
\text { num- } \\
\text { ber }\end{array}$} & \multicolumn{2}{|c|}{ Unsympathectomized side } & \multicolumn{2}{|c|}{ After sympathectomy } \\
\hline & $\begin{array}{l}\text { Resting } \\
\text { blood } \\
\text { flow }\end{array}$ & $\begin{array}{l}\text { Blood flow } \\
\text { following } \\
\text { heat test }\end{array}$ & $\begin{array}{l}\text { Resting } \\
\text { blood } \\
\text { flow }\end{array}$ & $\begin{array}{l}\text { Blood flow } \\
\text { following } \\
\text { heat test }\end{array}$ \\
\hline & $\begin{array}{c}\text { cc. per } 100 \mathrm{cc} \text {. } \\
\text { arm volume } \\
\text { per minute }\end{array}$ & $\begin{array}{l}\text { cc. per } 100 \mathrm{cc} . \\
\text { arm volume } \\
\text { per minute }\end{array}$ & $\begin{array}{c}\text { cc. per } 100 \mathrm{cc} . \\
\text { arm volume } \\
\text { per minute }\end{array}$ & $\begin{array}{c}\text { cc. per } 100 c c . \\
\text { arm volume } \\
\text { per minute }\end{array}$ \\
\hline 32 & 0.61 & 1.75 & 1.2 & 0.75 \\
\hline 33 & 0.65 & 1.75 & 1.1 & 0.75 \\
\hline
\end{tabular}

Case 2. A 56-year-old woman with five years history of Raynaud's disease of the fingers had left-sided sympathectomy performed by Dr. R. H. Smithwick of the Massachusetts General Hospital, with the typical results described in Case 1. One month later resting blood flow determinations were made and the heat test performed, comparing the left arm with the right (non-sympathectomized) sicle. As in the previous case the results (Table IV) show an absence of vasodilatation in response to the heat test on the sympathectomized side.

The above findings confirm Lewis's observation that vascular dilatation cluring the heat test is vasomotor in origin. They show also that active vasodilatation occurs as well as vasoconstrictor inhibition. Thus if the vascular dilatation following the heat test were due only to inhibition of vasoconstrictors, the increase in blood flow during the test would be the same as results from sympathetic block. Actually it was much greater, as the figures show (1.75:1.2 cc.).

In these experiments, as already noted, an actual diminution in blood flow occurs on the sympathectomized side cluring the heat test. This is readily explained by the vasodilatation in nor- mally innervated areas which causes a diversion of blood from sympathectomized segment.

Having shown that the vascular dilatation in the arm induced by the heat test is vasomotor in origin, we have performed this test on subjects with normal and with elevated blood pressure. If the vascular hypertonus in hypertension is due to vasoconstrictor impulses, the release of these inpulses by the heat test should result in a much greater increase in blood flow than in subjects with normal blood pressure.

Cases of benign hypertension were compared with controls, as shown in Table V. In twelve control subjects the degree of vascular dilatation produced by the heat test, as given by the average

TABLE V

Vasomotor dilatation induced by heat test*

\begin{tabular}{c|c|c|c|c|c}
\hline \hline $\begin{array}{c}\text { Case } \\
\text { num- } \\
\text { ber }\end{array}$ & Age & Sex & $\begin{array}{c}\text { Blood } \\
\text { pressure }\end{array}$ & $\begin{array}{c}\text { Blood flow } \\
\text { following } \\
\text { heat test }\end{array}$ & $\begin{array}{c}\text { Ratio of } \\
\text { increase over } \\
\text { resting flow }\end{array}$ \\
\hline & years & $\begin{array}{c}\text { cc.per 100 cc. } \\
\text { arm volume } \\
\text { per minute }\end{array}$ & \\
\hline
\end{tabular}

Controls

\begin{tabular}{|c|c|c|c|c|c|}
\hline 7 & 43 & M & $120 / 85$ & 3.3 & 23 \\
\hline 8 & 56 & $\mathrm{~F}$ & $\begin{array}{l}120 / 703 \\
140 / 78\end{array}$ & 5.5 & 4.24 \\
\hline 9 & 31 & $\mathrm{~F}$ & $115 / 80$ & 2.6 & 2.9 \\
\hline 10 & 29 & $\mathrm{M}$ & $120 / 70$ & 4.6 & 3.1 \\
\hline 11 & 27 & $\mathrm{~F}$ & $110 / 70$ & 3.5 & 1.85 \\
\hline 12 & 18 & $\mathrm{~F}$ & $120 / 70$ & 3.2 & 2.1 \\
\hline 13 & 47 & $\mathrm{~F}$ & $110 / 70$ & 7.0 & 4.6 \\
\hline 14 & 44 & $\mathrm{~F}$ & $120 / 70$ & 5.1 & 3.9 \\
\hline 15 & 22 & $\mathrm{~F}$ & $100 / 60$ & 1.75 & 2.7 \\
\hline 16 & 39 & $\mathrm{M}$ & $120 / 80$ & 2.2 & 3.7 \\
\hline 17 & 39 & $\mathrm{M}$ & $120 / 80$ & 3.0 & 4.2 \\
\hline 18 & 41 & $\mathrm{~F}$ & & 1.75 & 2.9 \\
\hline \multicolumn{3}{|c|}{ Average } & & 3.63 & $3.2 \dagger$ \\
\hline
\end{tabular}

Benign hypertension

\begin{tabular}{r|c|c|c|c|c}
\hline 6 & 44 & $\mathrm{M}$ & $238 / 160$ & 4.35 & 2.2 \\
7 & 43 & $\mathrm{M}$ & $160 / 130$ & 5.0 & 4.5 \\
8 & 54 & $\mathrm{~F}$ & $240 / 150$ & 2.4 & 4.7 \\
9 & 49 & $\mathrm{~F}$ & $270 / 110$ & 2.3 & 2.7 \\
10 & 50 & $\mathrm{~F}$ & $240 / 145$ & 4.3 & 3.3 \\
11 & 40 & $\mathrm{~F}$ & $160 / 110$ & 2.7 & 2.1 \\
12 & 32 & $\mathrm{~F}$ & $210 / 120$ & 10.5 & 5.8 \\
13 & 32 & $\mathrm{M}$ & $200 / 180$ & 2.8 & 2.5 \\
14 & 21 & $\mathrm{~F}$ & $190 / 140$ & 3.5 & 5.2 \\
15 & 34 & $\mathrm{M}$ & $180 / 130$ & 10.1 & 2.8 \\
\hline \multicolumn{3}{c}{ Average } & & 4.8 & $3.58 \dagger$ \\
\hline
\end{tabular}

* Resting flow values for each case may be scen in Table I.

$\dagger$ This figure is the average of the ratios. 
ratio of increased blood flow to the resting flow, is 3.2. In ten patients with benign hypertension the corresponding value is 3.58 .

The heat test after a severe exacerbation of hypertension was studied in Case 7 , already described. It was possible to perform the heat test on the same patient on different occasions at two different levels of blood pressure. When the blood pressure was $160 / 130$ the test produced an increase in blood flow from $1.1 \mathrm{cc}$. to $5.0 \mathrm{cc}$. During the exacerbation with change over to the malignant type and a blood pressure of $245 / 185$, the flow increased during the heat test from 1.05 cc. to $2.2 \mathrm{cc}$.

Discussion of the heat test including its application in coarctation of aorta. The fact that vasomotor arterial dilatation induced by the heat test causes no greater increase in blood flow in patients with hypertension than in normal subjects is strongly suggestive evidence against the vasomotor origin of the hypertonus in benign hypertension.

Similarly, in Case 7, if the exacerbation of the hypertension were vasomotor in origin we should have expected a greater increase in flow in response to the heat test with a blood pressure of $245 / 185 \mathrm{~mm}$. $\mathrm{Hg}$ than was obtained when the pressure was $160 / 130 \mathrm{~mm}$. Hg. Actually, for unexplained reasons, a smaller increase was observed.

A possible criticism may be made of our interpretation of the results obtained from the heat test; namely, that the reaction is a physiological response to heat resulting in an increase in blood flow to the periphery for the purpose of heat loss. The normal response in patients with hypertension might be explained in this way. The results of the heat test in cases of coarctation of the aorta may serve as an answer to this criticism. In this condition there is congenital obstruction of the aorta below the point of origin of the arteries to the upper extremities, resulting in hypertension in the upper and hypotension in the lower limbs.

Blumgart et al. (33) determined the arteriolar. pressure in the skin in such cases by the Weiss method, and found no difference in the upper and lower extremities. This led them to the conclusion that arteriolar constriction is absent in the upper part of the body in coarctation of the aorta. Graybiel, Allen and White (34) performed muscle biopsies on the arm and leg in patients with co- arctation of the aorta and found no difference in the histological appearance of the arterioles in the two situations.

We have studied four cases of coarctation of the aorta. In all, the blood pressure was increased in the arms (Table VI) and decreased in the legs. Evidence of collateral circulation was present in the chest, and x-rays showed erosion of the lower borders of the ribs due to enlargement of the intercostal arteries.

TABLE VI

Coarctation of aorta. Vasodilatation produced by heat test

\begin{tabular}{c|c|c|c|c|c|c}
\hline \hline $\begin{array}{c}\text { Case } \\
\text { num- } \\
\text { ber }\end{array}$ & Age & Sex & $\begin{array}{c}\text { Blood } \\
\text { pressure } \\
\text { (Arm) }\end{array}$ & $\begin{array}{c}\text { Resting } \\
\text { blood } \\
\text { flow }\end{array}$ & $\begin{array}{c}\text { Blood flow } \\
\text { following } \\
\text { heat test }\end{array}$ & Ratio \\
\hline & years & & mm. Hg & $\begin{array}{c}\text { cc. per } 100 \text { cc. } \\
\text { arm volume } \\
\text { per minute }\end{array}$ & $\begin{array}{c}\text { cc. per } 100 \text { cc. } \\
\text { arm volume } \\
\text { per minute }\end{array}$ & \\
34 & 21 & $\mathrm{~F}$ & $150 / 100$ & 0.96 & 7.7 & 8.1 \\
35 & 30 & $\mathrm{~F}$ & $170 / 110$ & 0.9 & 8.7 & 9.7 \\
36 & 30 & $\mathrm{~F}$ & $180 / 105$ & 1.1 & 7.3 & 6.6 \\
37 & 27 & $\mathrm{~F}$ & $160 / 100$ & 0.6 & 6.4 & 10.6 \\
\hline \multicolumn{3}{l}{ Average } & & 0.9 & 7.5 & $8.8 *$ \\
\hline
\end{tabular}

* This figure is the average of the ratios.

As shown in Table VI and Figure 5, the average resting blood flow in the arm in these patients was not increased but was definitely below normal $(0.9 \mathrm{cc}$.). The heat test, however, produced in all cases a very great increase in blood flow with an average of $7.5 \mathrm{cc}$., i.e. a ratio of 8.8 compared with ratios of 3.2 and 3.58 for normal subjects and patients with benign hypertension, respectively.

Since the resting flow in the arm is not increased in patients with coarctation of the aorta although the blood pressure is elevated, it follows on the basis of our previous arguments that arterial hypertonus is present in the upper limbs in this condition. When, however, vasomotor arterial dilatation is produced in the arm by the heat test the increase in flow is far greater than that produced in controls and in patients with generalized hypertension. The conclusion is that the vascular hypertonus in the upper extremities in coarctation of the aorta is vasomotor in origin, in contradistinction to the hypertonus of generalized (benign) hypertension.

The vasoconstriction in the upper part of the body in coarctation acts as a compensatory 


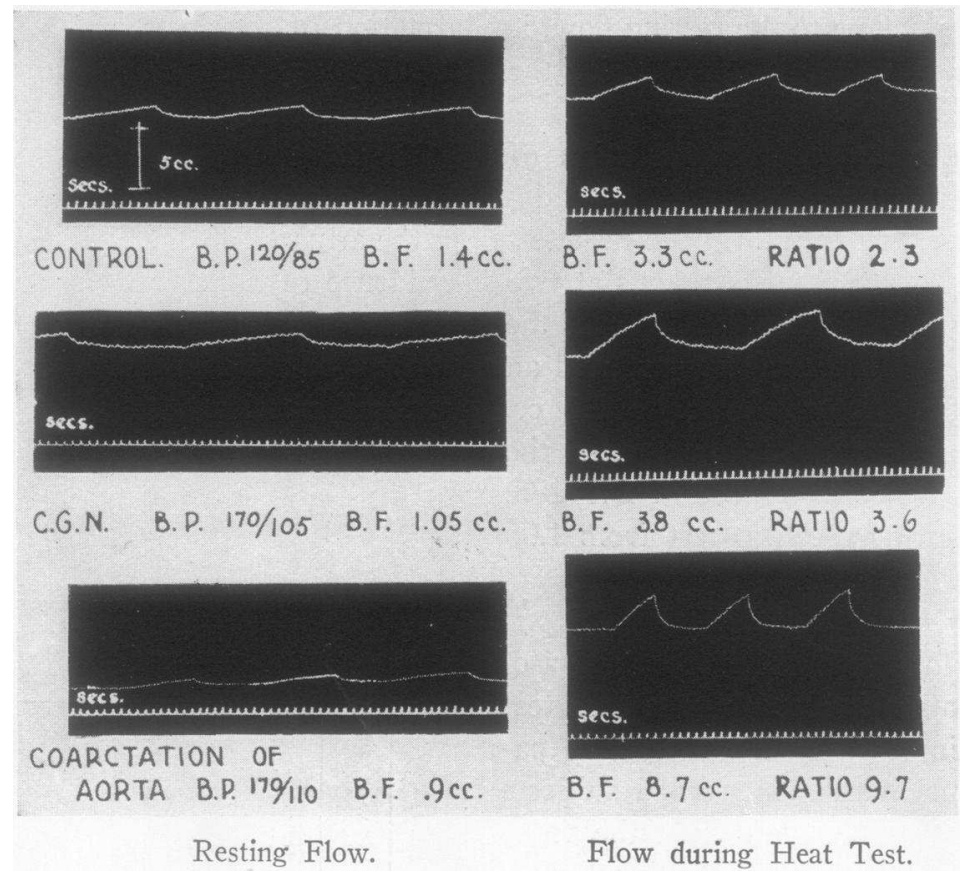

Fig. 5. Effect of Heat Test on Blood Flow.

B.P.-blood pressure.

C.G.N.-chronic glomerulonephritis.

B.F.-blood flow (cc. per 100 cc. arm volume per minute).

Ratio of blood flows indicates degree of vasodilatation produced by heat test.

mechanism and ensures the normal distribution of blood. Were it not present, the areas supplied from above the coarctation would receive an excessive blood supply at the expense of the rest of the body.

\section{Novocain injection of the vasomotor nerves}

In view of the fundamental importance of this question, i.e. the rôle of the vasomotor nerves in hypertension, a. more direct approach was made by comparing the increase in blood flow following anesthetization of the vasomotor nerves to the arm in patients with hypertension and in control subjects.

Principle and details of method. The vasomotor nerves to the arm emerge from the thoracic intervertebral foramina and join the sympathetic chain as it lies along the sides of the bodies of the dorsal vertebrae. The upper dorsal sympathetic ganglia can be anesthetized with relative ease by the method described by Labat (35) and White and White (36).
The skin is anesthetized with 2 per cent novocain at two points $3 \mathrm{~cm}$. laterally from the spines of the first and second dorsal vertebrae. At each point a lumbar puncture needle is introduced vertically as far as the outer surface of the underlying rib. The needle is now withdrawn slightly and reintroduced at an angle of $45^{\circ}$ medially and caudally. At a depth of 4 to $6 \mathrm{~cm}$., according to the build of the patient, the side of the body of the vertebra is encountered. The needle is now introduced a further $1 \mathrm{~cm}$. anteriorly and 5 to $10 \mathrm{cc}$. of 2 per cent novocain without epinephrine are slowly injected. At various stages of the procedure suction is applied to ensure that the pleural cavity has not been entered. A small injection ( $1 / 6$ grain) morphia is given beforehand.

Before applying this method, injections with colored dyes were made on cadavers until a successful technique was acquired. On opening the thorax the dyestuff is found below the pleura along the sides of the vertebral bodies, i.e. surrounding 
the sympathetic chain, and along the upper intercostal spaces.

The following are the criteria of a successful injection. A Horner's syndrome appears on the injected side within five to ten minutes. Anesthesia or hypo-esthesia is present over the first to third dorsal segmental skin areas. If these signs are absent, the injection is considered unsuccessful, and the experiment discarded. The blood flow in the arm begins to increase in five to ten minutes, reaches its maximum in fifteen to twenty minutes and then gradually falls to its previous value. If the sympathetic nerves are missed, no increase in blood flow is observed.

In one case iodized oil was injected with the needle in position. The $\mathrm{x}$-ray (Figure 6 ) shows the oil diffusely distributed along the sides of the bodies of the first to third dorsal vertebrae and in the posterior mediastinum behind the trachea.
This demonstrates that the injection was made at the correct site.

As a final check on the method, we compared the increase in flow produced in our two control subjects who had novocain injections with that observed in the two cases of Raynaud's disease already described, where sympathetic block was produced by alcohol injection and sympathectomy, respectively. The results are shown in Table $\operatorname{VII} A$, and it is seen that the increase in flow is essentially the same in both groups.

Injections were successfully made in four controls and five cases of hypertension. One of these was diagnosed as benign hypertension, two as malignant hypertension, one as secondary hypertension associated with chronic pyelonephritis, and one as acute glomerulonephritis. The last case was particularly interesting, as acute nephritis developed while the patient was under treatment for

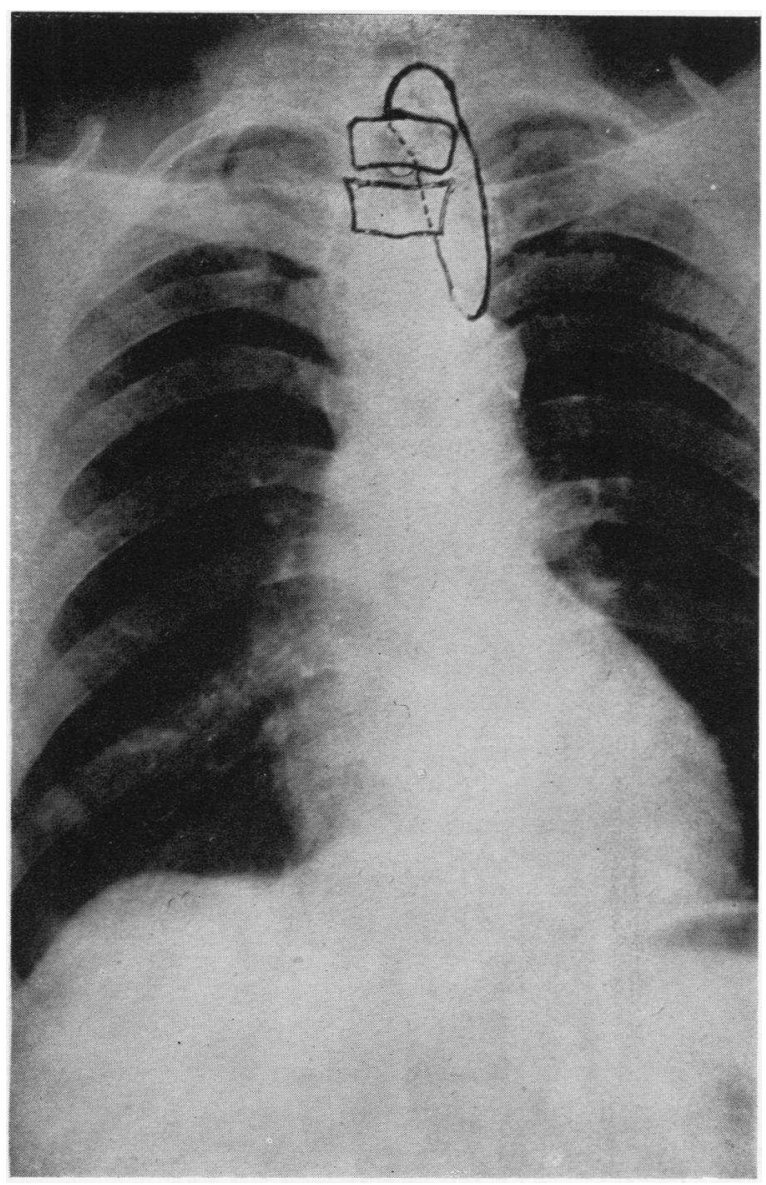

Fig. 6. X-RAy to Show Site of Injection of Novocain. The bodies of the first and second dorsal vertebrae and the distribution of the iodized oil are outlined. 
TABLE VII

Effect of sympathetic block on blood flow

\begin{tabular}{|c|c|c|c|c|c|c|c|}
\hline \multirow{2}{*}{ Case } & \multirow{2}{*}{ Age } & \multirow{2}{*}{ Sex } & \multirow{2}{*}{ Diagnosis } & \multirow{2}{*}{$\begin{array}{c}\text { Blood } \\
\text { pressure }\end{array}$} & \multicolumn{3}{|c|}{ Resting flow $24^{\circ} \mathrm{C}$. } \\
\hline & & & & & Before injection & After injection & Ratio \\
\hline & years & & & $m m . H g$ & $\begin{array}{c}\text { cc. per } 100 \text { cc. } \\
\text { arm volume } \\
\text { per minute }\end{array}$ & $\begin{array}{c}\text { cc. per } 100 \text { cc. } \\
\text { arm volume } \\
\text { per minute }\end{array}$ & \\
\hline
\end{tabular}

A. Controls

\begin{tabular}{l|l|l|l|l|l|l|l}
\hline 32 & 41 & $\mathrm{~F}$ & Raynaud's disease & Normal & 0.61 & 1.2 & 2.0 \\
33 & 22 & $\mathrm{~F}$ & Raynaud's disease & Normal & 0.65 & 1.1 & 1.7 \\
16 & 39 & $\mathrm{M}$ & Normal & 0.70 & 1.1 & 1.6 \\
17 & 39 & $\mathrm{M}$ & & Normal & 1.7 & 3.1 & 1.8 \\
\hline \multicolumn{3}{c}{ Average } & & & 0.91 & 1.6 & $1.8 \dagger$ \\
\hline
\end{tabular}

B. Hypertension

\begin{tabular}{|c|c|c|c|c|c|c|c|}
\hline $\begin{array}{r}21 \\
15 \\
29 \\
7 \\
31\end{array}$ & $\begin{array}{l}39 \\
34 \\
42 \\
44 \\
23\end{array}$ & $\begin{array}{l}\mathbf{M} \\
\mathbf{M} \\
\mathbf{M} \\
\mathbf{M} \\
\mathbf{F}\end{array}$ & $\begin{array}{l}\text { Malignant hypertension } \\
\text { Benign hypertension } \\
\text { Acute glomerulonephritis } \\
\text { Malignant hypertension } \\
\text { Chronic pyelonephritis }\end{array}$ & $\begin{array}{l}200 / 170 \\
180 / 130 \\
180 / 110 \\
245 / 185 \\
230 / 140\end{array}$ & $\begin{array}{l}0.5 \\
0.96 \\
1.45 \\
0.56 \\
1.3\end{array}$ & $\begin{array}{l}0.9 \\
1.6 \\
2.4 \\
0.88 \\
1.9\end{array}$ & $\begin{array}{ll}1.8 & (24.8)^{*} \\
1.7 & (34.0) \\
1.6 & (20.0) \\
1.6 & (17.3) \\
1.5 & (35.0)\end{array}$ \\
\hline \multicolumn{3}{|c|}{ Average } & & & 0.95 & 1.5 & $1.6 \dagger$ \\
\hline
\end{tabular}

* The figures in parenthesis are the maximum blood flows following reactive hyperemia.

$\dagger$ This figure is the average of the ratios.

chronic gonorrhea. The blood pressure rose acutely from $120 / 70$ to $190 / 100$, and the injection was made five days later. After three weeks' illness the patient died in uremia. An autopsy was performed and histological examination of the kidneys revealed an acute diffuse glomerulonephritis.

Results (Table VII and Figure 7). In four control subjects with normal blood pressure the increase in blood flow produced by sympathetic block was from $0.91 \mathrm{cc}$. to $1.6 \mathrm{cc}$, giving a ratio of 1.8. In the five cases with hypertension the average blood flows before and after injection were $0.95 \mathrm{cc}$. and $1.5 \mathrm{cc}$., giving a ratio of 1.6. The protocols of the five injection experiments are given in Table IX.

Discussion. The fact that anesthetization of the vasomotor nerves to the arm produces no greater increase in blood flow in patients with hypertension than in control subjects demonstrates that the increased peripheral resistance in such cases is not vasomotor in origin and is therefore to be considered as intrinsic hypertonus of the vessels themselves. It cannot be argued that the blood vessels in these cases were incapable of dilatation on account of organic changes, since we showed previously that they were capable of opening up in response to heat and reactive hyperemia. (These figures are given in parenthesis in Table VIIB.)

The statement has been made that patients with hypertension often show "instability" or "irritability" of the vasomotor system. This is brought forward as evidence for the vasomotor origin of hypertension. It is well known, however, that subjects with normal blood pressure may exhibit the same symptoms of "vasomotor instability." It is true that certain stimuli, e.g. heat, cold, and pain, produce greater fluctuations in blood pressure in patients with hypertension than in normal individuals. Such findings, however, do not prove that the hypertonus of arterial hypertension is vasomotor in origin. In view of our observations, a more probable explanation is that the same stimulus produces an abnormal reaction in patients with high blood pressure owing to the local fault in the blood vessels themselves.

The results of the heat test and of sympathetic block demonstrate that both vasoconstrictor and vasodilator fibers innervate the blood vessels of 


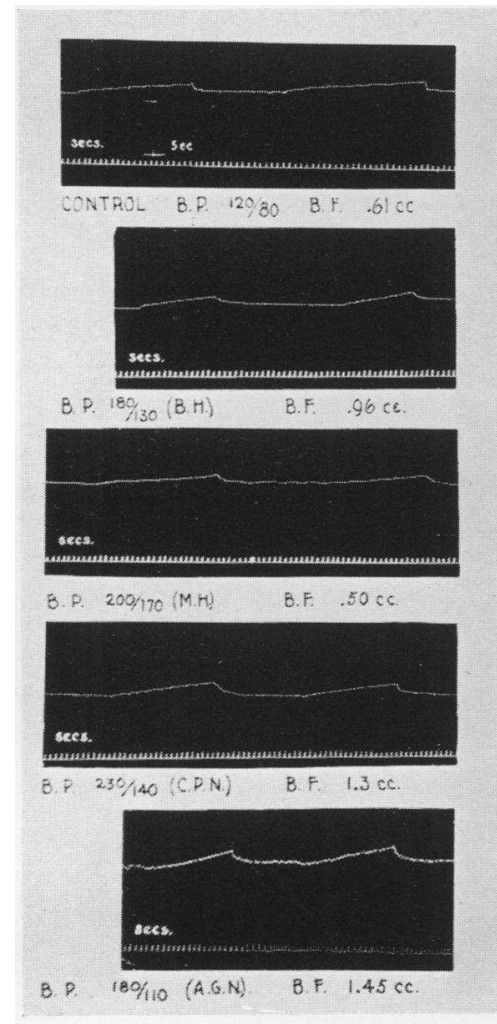

Before Injection.

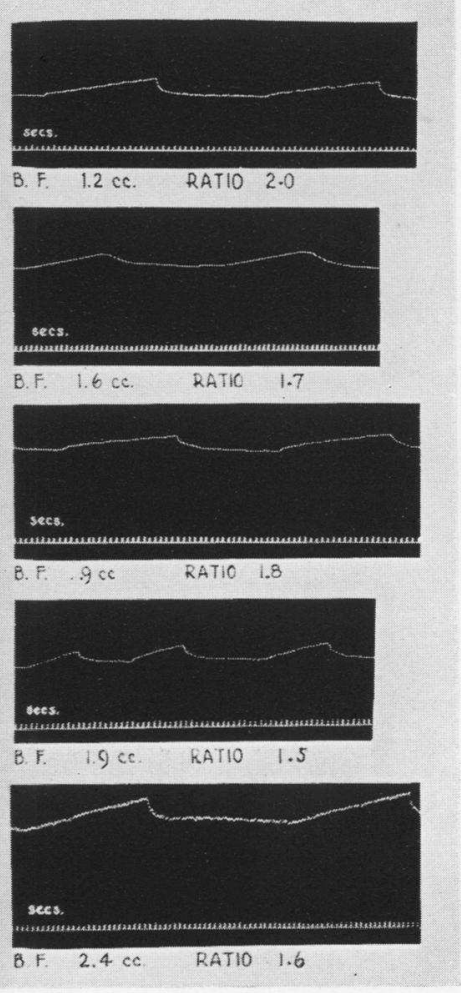

After Injection.

Fig. 7. Effect of Sympathetic Block on Blood Flow.

B.P.-blood pressure.

C.P.N.-chronic pyelonephritis.

B.F.-blood flow (cc. per $100 \mathrm{cc}$. arm volume per minute).

A.G.N.-acute glomerulonephritis.

B.H.-benign hypertension.

M.H.-malignant hypertension.

Ratio of blood flows indicates degree of vasodilatation produced by sympathetic block.

the arm. A comparison of the increase in blood flow produced by the two methods indicates that in this segment of the arm a greater effect is produced by vasodilator than by vasoconstrictor impulses, both in controls and in subjects with hypertension. In the types of hypertension we have studied it appears that normal vasomotor activity is superimposed on an intrinsic vascular hypertonus which is independent of the vasomotor nerves.

It has been suggested that the exacerbations of blood pressure or "vascular crises" occurring in hypertensive subjects are vasomotor in origin. We have already brought evidence against such a view, and the results of sympathetic block in the case in question (Table VIIB, Case 7) give further confirmation. Hence the acute exacerbation in this patient must be attributed to an increase in severity of the intrinsic vascular hypertonus and not to vasomotor hyperactivity.

\section{MALIGNANT HYPERTENSION AND SECONDARY (RENAL) HYPERTENSION}

\section{Literature}

Clinical experience and experimental evidence both indicate that hypertension follows certain forms of renal damage. In particular, circulatory obstruction to the kidney has been shown to increase the blood pressure in animals (37). 
Volhard (11) attributes "red" hypertension to arteriosclerosis (elastosis) of the renal vessels, while Fahr (38) considers that endarteritis and necrotizing arteriolitis in the kidney in malignant nephrosclerosis are responsible for the high blood pressure in this condition. The theories of production of renal hypertension have been ably discussed elsewhere (39). One hypothesis assumes that hypertension of renal origin is vasomotor in nature. Page (40) has recently shown that hypertension can be produced by clamping the renal artery in dogs even after removal of the extrinsic nerves to the kidney. In order to test the "reflex theory" on the motor side we have investigated cases of the malignant and secondary types by the methods outlined for benign hypertension.

\section{Results}

As shown in Table VIII and Figure 5, the heat test in cases of malignant and secondary hypertension produces an increase in blood flow which gives ratios of 3.2 and 3.1 respectively, compared with 3.2 and 3.58 for control subjects and patients with benign hypertension.

We have previously stated that of the patients in whom the sympathetic nerves were successfully injected with novocain two were cases of malignant and two cases of secondary hypertension (acute glomerulonephritis and chronic pyelonephritis). The results (Table VII $B$ and Figure 7) show that the increase in blood flow after sympathetic block is essentially the same as in normal subjects and in benign hypertension.

There is, therefore, no evidence on the motor side for the vasomotor origin of "renal" or malignant hypertension. We must conclude that in these cases, as in benign hypertension, the increased peripheral resistance is attributable to intrinsic hypertonus of the blood vessels themselves.

\section{DISCUSSION}

The above experiments have demonstrated that hypertension is due to vascular hypertonus which is generalized throughout the systemic circulation.

TABLE VIII

Vasomotor dilatation induced by heat test

\begin{tabular}{l|l|c|c|c|c|c|c|}
\hline $\begin{array}{c}\text { Case } \\
\text { num- } \\
\text { ber }\end{array}$ & Age & Sex & $\begin{array}{c}\text { Blood } \\
\text { pressure } \\
\text { (Arm) }\end{array}$ & $\begin{array}{c}\text { Resting } \\
\text { blood } \\
\text { flow }\end{array}$ & $\begin{array}{c}\text { Blood flow } \\
\text { following } \\
\text { heat test }\end{array}$ & $\begin{array}{c}\text { Ratio of in- } \\
\text { crease over } \\
\text { resting flow }\end{array}$ & Diagnosis \\
\hline$m m . H g$ & $\begin{array}{c}\text { cc. per } 100 \text { cc. } \\
\text { arm volume } \\
\text { per minute }\end{array}$ & $\begin{array}{c}\text { cc. per } 100 \text { cc. } \\
\text { arm volume } \\
\text { per minute }\end{array}$ & $\mid$ \\
\hline
\end{tabular}

Malignant hypertension

\begin{tabular}{r|l|l|l|l|l|l|l}
\hline 18 & 30 & $\mathrm{~F}$ & $270 / 180$ & 1.1 & 4.9 & 4.45 & \\
19 & 12 & $\mathrm{~F}$ & $210 / 170$ & 1.5 & 2.1 & 1.4 \\
20 & 40 & $\mathrm{~F}$ & $190 / 140$ & 2.3 & 2.75 & 1.2 & \\
21 & 39 & $\mathrm{M}$ & $200 / 170$ & 0.65 & 4.6 & 7.0 & \\
7 & 44 & $\mathrm{M}$ & $245 / 185$ & 1.05 & 2.2 & 2.1 \\
\hline \multicolumn{2}{c|}{ Average } & & & 1.3 & 3.3 & $3.2 \dagger$ & \\
\hline
\end{tabular}

Secondary hypertension

\begin{tabular}{l|l|l|l|l|l|l|l}
\hline 22 & 38 & $\mathrm{M}$ & $200 / 150$ & 1.4 & 3.8 & 2.7 & Chronic glomerulonephritis \\
23 & 40 & $\mathrm{M}$ & $170 / 105$ & 1.05 & 3.8 & 3.6 & Chronic glomerulonephritis \\
24 & 22 & $\mathrm{~F}$ & $150 / 110$ & 0.7 & 1.4 & 2.0 & Subacute glomerulonephritis \\
25 & 60 & $\mathrm{~F}$ & $170 / 105$ & 0.7 & 1.2 & 1.7 & Pyelonephritis. Kidney stones \\
26 & 15 & $\mathrm{~F}$ & $170 / 100$ & 0.7 & 2.8 & 4.0 & Subacute glomerulonephritis \\
$27 *$ & 42 & $\mathrm{M}$ & $210 / 105$ & 3.3 & 5.3 & 1.6 & Chronic glomerulonephritis \\
28 & 27 & $\mathrm{~F}$ & $200 / 110$ & 1.3 & 7.4 & 5.7 & Chronic glomerulonephritis \\
$29 *$ & 42 & $\mathrm{M}$ & $190 / 110$ & 0.7 & 3.0 & 4.3 & Acute glomerulonephritis \\
30 & 43 & $\mathrm{~F}$ & $250 / 150$ & 1.1 & 3.5 & 3.2 & Pyelonephritis. Kidney stones \\
31 & 23 & $\mathrm{~F}$ & $210 / 140$ & 1.8 & 3.7 & 2.1 & Chronic pyelonephritis \\
\hline \multicolumn{2}{c}{ Average } & & & 1.3 & 3.6 & $3.1 \dagger$ & \\
\hline
\end{tabular}


The hypertonus has been traced to a local disturbance in the blood vessels themselves, independent of the vasomotor nerves. Its nature and distribution are apparently the same in benign, malignant, and secondary (renal) hypertension, in both acute and chronic forms, and in acute exacerbations. The above evidence does not support Volhard's separation of hypertension associated with renal insufficiency ("pale" hypertension) on the basis of generalized vascular hypertonus, since cases of "red" hypertension show the same phenomenon. Whatever the nature of hypertension of renal origin, we have shown that on the motor side it is not produced by a nervous reflex. This study does not exclude the possibility of a circulating pressor substance which produces generalized peripheral vascular spasm but, as we have stated above, the existence of such a substance has not yet been satisfactorily demonstrated.

Among the surgical procedures which have been devised for the treatment of hypertension, section of the vasomotor nerves, particularly those to the splanchnic area, is amongst the most recent. The rationale of the operation is based on two assumptions: (1) That hypertension is due to excessive vasoconstriction in the splanchnic area; (2) that the vasoconstriction is brought about by the vasomotor nerves. Since our results do not support either of these assumptions there would appear to be no rational basis for such operative procedures. Theoretically, some fall in blood pressure may follow sympathectomy in patients with hypertension, since the normal vasoconstrictor tone is thereby abolished; but the intrinsic vascular spasm responsible for the hypertension would be expected to persist after the vasomotor nerves are cut.

\section{SUMMARY AND CONCLUSIONS}

1. Determinations of resting blood flow in the arm in various types of hypertension (benign, malignant, and secondary) give an average value no greater than that obtained from subjects with normal blood pressure. This indicates that increased vascular resistance in the different types of hypertension is not confined to the splanchnic area but is generalized throughout the systemic circulation.
TABLE IX

Protocols

Time $\left|\begin{array}{c}\hline \text { Blood flow } \\ \hline \begin{array}{c}c c \text { per } 100 \text { cc. } \\ \text { per minute }\end{array}\end{array}\right|$ Comment

Case 31. Chronic pyelonephritis. Age 23. Blood pressure 230/140

\begin{tabular}{|c|c|c|}
\hline $\begin{array}{l}2: 10 \\
2: 11 \\
2: 15 \\
2: 18 \\
2: 22\end{array}$ & $\begin{array}{l}1.4 \\
1.3 \\
1.2 \\
1.9\end{array}$ & $\begin{array}{l}\text { Needle in position } \\
5 \text { cc. novocain injected } \\
5 \text { cc. novocain injected } \\
\text { Horner's syndrome present. Anes- } \\
\text { thesia 1st to 3rd intercostal spaces } \\
\text { and under arm }\end{array}$ \\
\hline $2: 30$ & 1.15 & \\
\hline
\end{tabular}

Case 7. Malignant hypertension (Exacerbation). Age 43. Blood pressure 245/185

\begin{tabular}{|c|c|c|}
\hline $\begin{array}{l}2: 00 \\
2: 03 \\
2: 08\end{array}$ & $\begin{array}{l}0.62 \\
0.56 \\
1.35\end{array}$ & $\begin{array}{l}\text { Needle in position } \\
10 \text { cc. novocain injected } \\
\text { Horner's syndrom present. Anes- } \\
\text { thesia 1st to 3rd intercostal spaces } \\
\text { and under arm }\end{array}$ \\
\hline $\begin{array}{l}2: 20 \\
2: 30\end{array}$ & $\begin{array}{l}0.85 \\
0.63\end{array}$ & \\
\hline
\end{tabular}

Case 29. Acute glomerulonephritis. Age 42 . Blood pressure 180/110

\begin{tabular}{l|l|l}
\hline $2: 15$ & 1.7 & $\begin{array}{l}\text { Needle in position } \\
\text { 10 cc. novocain injected } \\
2: 16\end{array}$ \\
$2: 22$ & 1.9 & $\begin{array}{l}\text { Horner's syndrome present } \\
\text { Anesthesia 1st to 3rd intercostal } \\
\text { spaces and under arm }\end{array}$ \\
\hline $2: 25$ & 2.4 & \\
\hline $2: 30$ & 2.5 & \\
\hline
\end{tabular}

Case 15. Benign hypertension. Age 34 . Blood pressure 180/130

\begin{tabular}{|c|c|c|}
\hline $\begin{array}{l}2: 00 \\
2: 02 \\
2: 05 \\
2: 15\end{array}$ & $\begin{array}{l}0.88 \\
0.83 \\
0.96 \\
1.6\end{array}$ & $\begin{array}{l}\text { Needles in position } \\
\text { Injection } 10 \mathrm{cc} \text {. novocain } \\
\text { Horner's syndrome present } \\
\text { Anesthesia 1st to 3rd intercostal } \\
\text { spaces and under arm }\end{array}$ \\
\hline
\end{tabular}

Case 21. Malignant hypertension. Age 39. Blood pressure 200/170

\begin{tabular}{l|l|l}
\hline $2: 02$ & 0.5 & Needles in position \\
$2: 04$ & 0.4 & 10 cc. novocain injected \\
$2: 19$ & 0.9 & $\begin{array}{l}\text { Horner's syndrome present } \\
\text { Anesthesia 1st to 3rd intercostal } \\
\text { spaces and under arm }\end{array}$ \\
\hline
\end{tabular}


2. Patients with hypertension show increase in blood flow in response to heat and reactive hyperemia equal in degree to that produced in normal individuals, showing that the blood vessels in hypertension are capable of considerable dilatation and indicating that the increased peripheral resistance is due to hypertonus and not to organic changes in the vessel walls.

3. Sympathetic vasodilatation produced by the " heat test" produces no greater increase in blood flow in subjects with high blood pressure than in normal individuals, suggesting that the vascular hypertonus is not vasomotor in origin.

4. Patients with coarctation of the aorta, on the other hand, show a greater increase in blood flow in the arm in response to the heat test than controls or patients with generalized hypertension. This demonstrates that vasoconstriction of sympathetic origin is present in the upper extremities in coarctation of the aorta, and affords confirmatory indirect evidence that the hypertonus in generalized hypertension is not of vasomotor origin. Sympathetic vasoconstriction in the upper extremities in coarctation of the aorta may be regarded as a compensatory mechanism which maintains the normal distribution of blood throughout the body.

5. Anesthetization with novocain of the vasomotor nerves to the arm produces the same increase in flow in normal subjects and patients with hypertension, proving that the vascular hypertonus is independent of the vasomotor nerves, and that this hypertonus must therefore be regarded as intrinsic spasm of the blood vessels themselves.

6. Acute exacerbation of hypertension with change from the benign to the malignant type has been observed in one case. Such exacerbation is apparently not due to increased vasomotor activity but must be attributed to an increase in the intrinsic vascular hypertonus.

7. The above conclusions apply to all types of hypertension studied; namely, benign hypertension, malignant hypertension, and " renal " hypertension associated with acute and chronic glomerulonephritis and chronic pyelonephritis; hence there is no physiological evidence for the separation into "organic" and "functional" types or for the assumption that renal hypertension is due to vasomotor hypertonus.
8. It has been shown in both normal subjects and in patients with hypertension that there is vasoconstrictor and vasodilator innervation to the blood vessels of the arm. In this region greater variations in blood flow are produced by vasodilator than by vasoconstrictor impulses. In the types of hypertension studied, it appears therefore that normal vasomotor activity is superimposed on the intrinsic vascular hypertonus.

9. Surgical procedures aiming at the relief of high blood pressure by sympathectomy do not abolish the vascular hypertonus which is fundamentally responsible for the hypertension.

We desire to thank Dr. Soma Weiss for his assistance and advice and Dr. James White for his instruction in the method of novocain injection. We are indebted for cases of coarctation of the aorta and Raynaud's disease to Dr. Paul D. White, Dr. F. C. Eppinger, Dr. R. H. Smithwick and Dr. W. R. Wegner.

\section{BIBLIOGRAPHY}

1. Lauter, S., and Baumann, H., Uber der Kreislauf bei Hochdruck, Arteriosklerose, und Apoplexie. Ztschr. f. klin. Med., 1928, 109, 415.

2. Burwell, C. S., and Smith, W. C., The output of the heart in patients with abnormal blood pressures. J. Clin. Invest., 1929 7, 1.

3. Weiss, S., and Ellis, L. B., The quantitative aspects and dynamics of the circulatory mechanism in arterial hypertension. Am. Heart J., 1929-30, 5. 448.

4. Austrian, C. R., The viscosity of the blood in health and disease. Bull. Johns Hopkins Hosp., 1911. $22,9$.

5. Linder, G. C., Lundsgaard, C., Van Slyke, D. D., and Stillman, E., Changes in the volume of plasma and absolute amount of plasma proteins in nephritis. J. Exper. Med., 1924, 39, 921.

6. Lewis, T., and Grant, R., Observations upon reactive hyperaemia in man. Heart, 1925, 12, 73.

7. Longcope, $\mathrm{W}$. T., and McClintock, A. T., The effect of permanent constriction of the splanchnic arteries and the association of cardiac hypertrophy with arteriosclerosis. Arch. Int. Med., 1910, 6, 439.

8. Jansen, W. H., Tams, W., and Achelis, H., Blutdruckstudien. I. Zur dynamik des Blutdrucks. Deutsches Arch. f. klin. Med., 1924, 144, 1.

9. Brown, G. E., Sympathectomy for early malignant hypertension. M. Clin. North America, 1934, 18, 577.

10. Craig, W. M., and Brown, G. E., Unilateral and 
bilateral resection of major and minor splanchnic nerves. Arch. Int. Med., 1934, 54, 577.

11. Volhard, F., Die doppelseitigen hämatogenen Merenkrankungen. Handbuch der Inneren Medizin, v. Bergmann, G., and Staehlin, R. J. Springer, Berlin, 1931, Volume 6.

12. de Wesselow, O. L. V. S., and Griffiths, W. J., On the question of pressor bodies in the blood of hypertensive subjects. Brit. J. Exper. Path., 1934, $15,45$.

13. Page, I. H., Pressor substances from the body fluids of man in health and disease. J. Exper. Med., $1935,61,67$.

14. Aitken, R. S., and Wilson, C., An attempt to demonstrate a pressor substance in the blood in malignant hypertension. Quart. J. Med., 1935, 4, 179.

15. Brodie, T. G., The determination of the rate of blood flow through an organ. Seventh International Physiol. Congress, August, 1907. Quoted from Hewlett and van Zwaluwenburg (16).

16. Hewlett, A. W., and van Zwaluwenburg, J. G., The rate of blood flow in the arm. Heart, 1909, 1, 87.

17. Prinzmetal, M., Studies on the mechanism of circulatory insufficiency in sclerodactylia. Arch. Int. Med. (In press).

18. Grollman, A., Physiological variations in the cardiac output of man. III. The effect of the ingestion of food in the cardiac output, pulse rate, blood pressure, and oxygen consumption of man. Am. J. Physiol., 1929, 89, 366.

19. Weiss, S., Haynes, F. W., and Shore, R., A study of factors determining pulse pressure in arterial hypertension. (In preparation.)

20. Hines, E. A., Jr., and Brown, G. E., A standard test for measuring the variability of blood pressure: its significance as an index of the prehypertensive state. Ann. Int. Med., 1933, 7, 209.

21. Pal, J., Utber Härte und Füllung der tastbaren arterien. Med. Klin., 1925, 21, 1378.

22. Brown, S., and Alexander, B., Duroziez's sign in normal subjects and in patients with arterial hypertension with special reference to its relation to capillary pulsation and the forward flow of blood during diastole. J. Clin. Invest., 1935, 14, 285.

23. Lange, F., Die Funktion der Blutstrombahn bei Hypertonie. Deutsches Arch. f. klin. Med., 1928, 158, 214.

24. Lian, C., Stoicesco, S., and Vidrasco, C., De l'état du système nerveux végétatif dans l'hypotension et l'hypertension artérielles permanentes. Presse méd., 1929, 37, 1309.

25. Freeman, N., The blood flow in man. Am. J. Physiol. (In press.)

26. Kernohan, J. W., Anderson, E. W., and Keith, N. M., The arterioles in cases of hypertension. Arch. Int. Med., 1929, 44, 395.

27. Moritz, A. R., and Oldt, M. R., Arteriolar changes in essential hypertension. Am. J. Path. (Abstract), 1935, 11, 885.

28. Raab, W., Die Beziehungen zwischen $\mathrm{CO}_{2}$-Spannung und Blutdruck bei normalen und Hypertonikern. Beitrag zur Pathogenese der nicht "nephritischen" Hypertonien. Ztschr. f. d. ges. exper. Med., 1929, 68, 337.

29. Pal, J., Die Gefässkrisen. S. Hirzel, Leipzig, 1905. (Footnote 10.)

30. Baráth, E., Arterial hypertension and physical work. Arch. Int. Med., 1928, 42, 297.

31. Lewis, T., and Pickering, G. W., Vasodilatation in the limbs in response to warming the body; with evidence for sympathetic vasodilator nerves in man. Heart, 1931, 16, 33.

32. Gibbon, J. H., Jr., and Landis, E. M., Vasodilatation in the lower extremities in response to immersing the forearms in warm water. J. Clin. Invest., 1932, 11, 1019.

33. Blumgart, H. L., Lawrence, J. S., and Ernstene, A. C., The dynamics of the circulation in coarctation (stenosis of the isthmus) of the aorta of the adult type. Arch. Int. Med., 1931, 47, 806.

34. Graybiel, A., Allen, A. W., and White, P. D., A histological study of the arterioles of the muscle and skin from the arm and leg in individuals with coarctation of the aorta. J. Clin. Invest., 1935, $14,52$.

35. Labat, G., Regional anaesthesia. W. B. Saunders Co., Philadelphia, 1922, p. 223.

36. White, J. C., and White, P. D., Angina pectoris. Treatment with paravertebral alcohol injections. J. A. M. A., 1928, 90, 1099.

37. Goldblatt, H., Lynch, J., Hanzal, R. F., and Summerville, W. W., Studies on experimental hypertension. I. The production of persistent elevation of systolic blood pressure by means of renal ischemia. J. Exper. Med., 1934, 59, 347.

38. Fahr, Th., Handbuch der speziellen pathologischen Anatomie und Histologie, Henke, F., und $\mathrm{Lu}$ barsch, O. J. Springer, Berlin, 6, 1-1925; 21934.

39. Fishberg, A., Hypertension and nephritis. Lea and Febiger, Philadelphia, 1934, 3d ed.

40. Page, I. H., The relationship of the extrinsic renal nerves to the origin of experimental hypertension. Am. J. Physiol., 1935, 112, 166.

41. Kimmelstiel, P., and Wilson, C., Benign and malignant hypertension and nephrosclerosis. A clinical and pathological study. (In press.)

42. Gross, L., Studies on the circulation of the kidney in relation to architecture and function of the organ in health and disease. I and II. J. Med. Research, 1917, 36, 327; 1918, 38, 379.

43. Baehr, G., and Ritter, S. A., The arterial supply of the kidney in nephritis. Its relation to the clinical picture. Arch. Path., 1929, 7, 458. 